\title{
Use of Modern Family Planning Methods among Women of South-Western Nigeria: A Snapshot
}

\section{Joe-Ikechebelu NN1,2, Azuike EC1,2,3*, Agbor IE ${ }^{4}$, Nwankwo BE 2,5 , Onyemachi $\mathrm{PE}^{6}$, Obi IV7, 0 kolie $\mathrm{VE}^{8}$ and $\mathrm{Obi} \mathrm{KM}{ }^{5}$ \\ ${ }^{1}$ Department of Community Medicine and Primary Healthcare, Chukwuemeka Odumegwu Ojukwu University/University Teaching Hospital, Awka, Anambra}

\begin{tabular}{|c|}
\hline Research Article \\
Volume 2 Issue 2 \\
Received Date: August 10, 2018 \\
Published Date: October 22, 2018 \\
\hline
\end{tabular}
State, Nigeria

${ }^{2}$ Health Promotion and Practice Research Unit (HPPRU), Chukwuemeka Odumegwu Ojukwu University Teaching Hospital, Awka, Anambra State, Nigeria

${ }^{3}$ Foundation for Health and Development in Nigeria

${ }^{4}$ Department of Community, University of Calabar, Calabar, Cross River State, Nigeria

${ }^{5}$ Department of ENT, Chukwuemeka Odumegwu Ojukwu University Teaching Hospital, Awka, Anambra State, Nigeria ${ }^{6}$ Department of Community Medicine, Abia State University, Uturu, Abia State, Nigeria

${ }^{7}$ Medserve Healthcare Consultancy Services

${ }^{8}$ Department of Obstetrics and Gynaecology, Nnamdi Azikiwe University Teaching Hospital, Nnewi, Anambra State, Nigeria

*Corresponding author: Azuike EC, Department of Community Medicine, Nnamdi Azikiwe University Teaching Hospital, Nnewi, Anambra State, Nigeria, Email: emmanazuike@yahoo.com

\section{Abstract}

Introduction: The use of modern family planning methods equips couple and single women of reproductive age with the tool to decide when they want to get pregnant, to decide the number of children want to have and the spacing in between childbirths. This has enormous benefits for the women, families and the society at large.

Methods: This study was a secondary analysis of the 2013 Nigerian Demographic and Health Survey (NDHS). Only the women of reproductive age (15 to 49 years) who reside in the South-Western geo-political zone of Nigeria were included in the study. Data was analysed using Stata 12.1 software and summarized using proportions. Logistic regression was used to determine the factors that affect the use of modern family planning methods. Results were presented as tables.

Results: A total of 3,882 women participated in the study. The most common age group was the 25 to 29 years age group (28.77\%). The mean age was $30.7 \pm 6.2$ years. Modern family planning methods was being used by $23.47 \%$ of the respondents. Majority (91.32\%) of the respondents were married. Lagos state had the highest proportion of women using modern methods (28.98\%). Women who had a minimum of secondary education were 1.2 times more likely than those with only primary education to use modern family planning methods $(\mathrm{CI}=1.035983-1.454942$, $\mathrm{p}=$ 


\section{Epidemiology international journal}

0.018). Older women ( $\geq 25$ years) were 1.4 times more likely to use modern family planning than the younger women ( $C I=1.171135-1.872016, p=0.001)$. Urban women were twice more likely than the rural women to use modern family planning methods ( $\mathrm{CI}=1.674996-2.447385, \mathrm{p}=<0.001)$.

Conclusion: In conclusion, the present study has demonstrated that the likelihood of using modern family planning among women in the South-Western geo-political zone of Nigeria is increased by the following variables: having at least secondary education; being 25 years old or more and urban residence. We recommend the consideration of these factors in the planning of interventions to increase uptake of modern family methods in Nigeria.

Keywords: Modern family planning; South-Western Nigerian Women

\section{Introduction}

Family planning services are defined as "educational, comprehensive medical or social activities which enable individuals, including minors, to determine freely the number and spacing of their children and to select the means by which this may be achieved" [1]. According to Merriam-Webster dictionary, Family planning can be defined as planning intended to determine the number and spacing of one's children through birth control [2]. Family planning enables a couple to decide when they want to achieve pregnancy and also when to avoid pregnancy. It also helps a couple to decide the number of children they want to have and the spacing between each conception.

Unintended pregnancy is a major public health problem that affects not only the individuals directly involved but also the society [3]. This is because a couple may be overburdened with the number of children they have to provide for, thereby falling deeper into poverty. Poverty affects all health indices directly or indirectly. Unintended pregnancy can lead to the consideration of abortion. In a country like Nigeria where abortion is not legal, one may resort to illegal abortion in the hands of unqualified health personnel which may result in a myriad of problems. These are all preventable with the use of modern family planning methods. Nigeria is currently the most populated country in Africa and the 7th most populated country in the World [4]. Currently, Nigeria's population is growing at a rate of $2.6 \%$ annually according to the World Bank [5]. Among the ten most populated countries in the world, Nigeria's population is growing the most rapidly.

Consequently, the population of Nigeria is projected to surpass that of the United States by 2050, at which point Nigeria would become the third largest country in the world [6]. The effects of uncontrolled population growth are enormous. Some of the effects are depletion of resources, human congestion, weather modification, high unemployment rate and environmental degradation. The 2013 Nigeria Demographic and Health Survey reported that 85 percent of women and 95 percent of men knew about a contraceptive method [7]. Overall, 15 percent of currently married women in Nigeria were using a contraceptive method, an increase of only 2 percentage points since the 2003 NDHS [7]. The overall contraceptive prevalence among women in Nigeria was 16 percent [7]. The South West zone had the highest proportion of women currently using a family planning method (38\%), followed by the South East (29\%). The lowest proportion of married women using a family planning method was in the North East (3 percent). Among the states, Lagos (South-West) and Kwara (North-Central) states had the highest percentages of women using any method (48 percent and 40 percent, respectively).

Although the South-West had the highest proportion of women using contraceptives, it is good to disaggregate the data and look at the different states and some determinants of use of modern family planning methods. The aim of this study was to narrow into the South-Western geo-political zone of Nigeria using data generated by the 2013 Nigeria Demographic and Health Study (NDHS) and explore some possible determinants of use of modern family planning methods.

\section{Methodology}

The Demographic and Health Surveys (DHSs) are nationally-representative household surveys that provide data for a wide range of monitoring and impact evaluation indicators in the areas of population, health, and nutrition for low and middle income countries [8]. This study used Nigeria Demographic and Health Survey 2013 dataset. Ethical approval was obtained from the ethical committee of Chukwuemeka Odumegwu Ojukwu University Teaching Hospital, Awka. Only females of reproductive age (15 to 49 years) from the South-Western geo-political zone of the 
country were included in the study. The women were 3,882 in number. Data was analysed using Stata data analysis software Version 12.1.

Some basic characteristics of the women were explored including: the State they reside, the age of the women, the highest educational level they attained, their place of residence (urban/rural), current method of family planning, current marital status. Frequencies and percentages were displayed in tables. Binomial logistic regression was used to establish the determinants of use of modern family planning among the women. The dependent variable was the current family method of the women. This variable was originally grouped into four possible outcomes: No family planning method, traditional method, folkloric method and modern method. But for the purpose of this study, this variable was re-coded into only two possible outcomes: Modern family planning method and others. The independent variables were: educational level, the geo-political zone the women belong to, age of the women, place of residence (urban/rural) and marital status of the women. Some of the independent variables which had more than two categories were re-coded into only two categories. The educational level was re-coded into two categories: minimum of secondary school and primary school or less. Age was re-coded into two categories: 25 years or more and 24 years or less. Marital status was re-coded into two categories: currently married and others. The p-value was set at 0.05 meaning that any p-value that is less than 0.05 was considered statistically significant.

\section{Results}

Table 1 shows the distribution of the respondents according to their states. Lagos State had the highest percentage of respondents (24.45\%) while Ekiti State had the lowest (13.65\%).

\begin{tabular}{|c|c|c|}
\hline $\begin{array}{c}\text { State of } \\
\text { residence }\end{array}$ & Frequency & Percentage \\
\hline Oyo & 661 & 17.03 \\
\hline Osun & 558 & 14.37 \\
\hline Ekiti & 530 & 13.65 \\
\hline Ondo & 648 & 16.69 \\
\hline Lagos & 949 & 24.45 \\
\hline Ogun & 536 & 13.81 \\
\hline Total & 3,882 & 100.0 \\
\hline
\end{tabular}

Table 1: Distribution of the respondents according to States in the South-west geo-political zone of Nigeria.

Table 2 shows the age distribution of the respondents. The most common age group was the 25 to 29 years age group which made up $28.77 \%$ of all the respondents. The least represented age groups were the
15-19 years and the 45-49 years age groups (2.06\%). The mean age was $30.7 \pm 6.2$ years.

\begin{tabular}{|c|c|c|}
\hline Age group (years) & Frequency & Percentage \\
\hline $15-19$ & 80 & 2.06 \\
\hline $20-24$ & 509 & 13.11 \\
\hline $25-29$ & 1117 & 28.77 \\
\hline $30-34$ & 1079 & 27.79 \\
\hline $35-39$ & 730 & 18.80 \\
\hline $40-44$ & 287 & 7.39 \\
\hline $45-49$ & 80 & 2.06 \\
\hline Total & 3,882 & 100.00 \\
\hline
\end{tabular}

Table 2: Age distribution of the respondents (years)

Table 3 shows the respondents' highest level of education. Those that had no education made up $11.00 \%$ of the respondents. The commonest group was those who had secondary education (48.40\%).

\begin{tabular}{|c|c|c|}
\hline $\begin{array}{c}\text { Highest Educational } \\
\text { level }\end{array}$ & Frequency & Percentage \\
\hline No formal education & 427 & 11.00 \\
\hline Primary & 962 & 24.78 \\
\hline Secondary & 1879 & 48.40 \\
\hline Higher & 614 & 15.82 \\
\hline Total & 3882 & 100.00 \\
\hline
\end{tabular}

Table 3: Highest Educational level of the respondents.

Table 4 shows the place of residence of the respondents. A greater proportion of the respondents are urban dwellers (68.96\%).

\begin{tabular}{|c|c|c|}
\hline $\begin{array}{c}\text { Place of } \\
\text { residence }\end{array}$ & Frequency & Percentage \\
\hline Urban & 2,677 & 68.96 \\
\hline Rural & 1205 & 31.04 \\
\hline Total & 3882 & 100.00 \\
\hline
\end{tabular}

Table 4: Respondents' place of residence.

Table 5 shows the current method of family planning the respondents were using. Modern method was being used by $23.47 \%$ of the respondents. More than half $(64.58 \%)$ were not using any method.

\begin{tabular}{|c|c|c|}
\hline $\begin{array}{c}\text { Method of family } \\
\text { planning }\end{array}$ & Frequency & Percentage \\
\hline No method & 2,507 & 64.58 \\
\hline Folkloric method & 51 & 1.31 \\
\hline Traditional method & 413 & 10.64 \\
\hline Modern method & 911 & 23.47 \\
\hline Total & 3,882 & 100.00 \\
\hline
\end{tabular}

Table 5: Current method of family planning used by the respondents. 


\section{Epidemiology international journal}

Table 6 shows the marital status of the respondents. Majority (91.32\%) of the respondents were married.

\begin{tabular}{|c|c|c|}
\hline Current marital status & Frequency & Percentage \\
\hline Never in union & 89 & 2.29 \\
\hline Married & 3545 & 91.32 \\
\hline Living with a partner & 170 & 4.38 \\
\hline Widowed & 23 & 0.59 \\
\hline Divorced & 20 & 0.52 \\
\hline No longer living together/separated & 35 & 0.90 \\
\hline Total & 3882 & 100.00 \\
\hline
\end{tabular}

Table 6: Respondents' current marital status.

Table 7 shows the proportion of women in each state that use modern family planning methods. Lagos state had the highest proportion of women using modern methods (28.98\%).

\begin{tabular}{|c|c|c|c|}
\hline & \multicolumn{3}{|c|}{ Family planning method } \\
\hline & \multicolumn{3}{|c|}{ Frequency (\%) } \\
\hline State & Modern method & Others & Total \\
\hline Oyo & $149(22.54)$ & $512(77.46)$ & $661(100.00)$ \\
\hline Osun & $155(27.78)$ & $403(72.22)$ & $558(100.00)$ \\
\hline Ekiti & $107(20.19)$ & $423(79.81)$ & $720(100.00)$ \\
\hline Ondo & $108(16.67)$ & $540(83.33)$ & $648(100.00)$ \\
\hline Lagos & $275(28.98)$ & $674(71.02)$ & $949(100.00)$ \\
\hline Ogun & $117(21.83)$ & $419(78.17)$ & $536(100.00)$ \\
\hline Total & $911(23.47)$ & $2,971(76.53)$ & $3,882(100.00)$ \\
\hline
\end{tabular}

Table 7: Respondents' use of modern family planning method by state of residence.

Table 8 shows the odds ratios for the predictors of use of modern family planning methods. The women who had at least secondary education were 1.2 times more likely than those who had less than secondary education to use modern family planning methods. Women who were 25 years or more were 1.4 times more likely than those who were less than 25 years to use modern family planning methods. The women who lived in urban areas were twice more likely to use modern family planning methods than those who lived in the rural areas. All the above were statistically significant. Marital status had no effect on the use of modern family planning methods.

\begin{tabular}{|c|c|c|c|}
\hline \multirow[b]{2}{*}{ Variable } & \multicolumn{2}{|c|}{ Use of modern method of family planning } & \multirow[b]{2}{*}{ p-value } \\
\hline & Odds ratio & $95 \%$ confidence interval & \\
\hline \multicolumn{4}{|l|}{ Education } \\
\hline$\geq$ Secondary school & 1.228 & $1.035983-1.454942$ & 0.018 \\
\hline$\leq$ Primary school & 1.000 & & \\
\hline \multicolumn{4}{|l|}{ Age (years) } \\
\hline$\geq 25$ & 1.481 & $1.171135-1.872016$ & 0.001 \\
\hline$\leq 24$ & 1.000 & & \\
\hline \multicolumn{4}{|l|}{ Residence } \\
\hline Urban & 2.025 & $1.674996-2.447385$ & $<0.001$ \\
\hline Rural & 1.000 & & \\
\hline \multicolumn{4}{|l|}{ Marital Status } \\
\hline Married & 1.036 & $0.7869863-1.364416$ & 0.800 \\
\hline Others & 1.000 & & \\
\hline
\end{tabular}

Table 8: Odds Ratio for Correlates of use of Modern Family planning Methods among the respondents.

\section{Discussion}

The commonest state among the respondents was Lagos state $(24.45 \%)$, while the least represented state was Ekiti State (13.65\%). The most common age group was the 25-29 years age group which made up $28.77 \%$ of all the respondents, while the least represented age groups were the 15-19 years (2.06\%) and the 45-49 years $(2.06 \%)$ age groups. Almost half $(48.40 \%)$ of the 


\section{Epidemiology international journal}

women who participated in the present study had secondary education. Majority of the women (91.32\%) were married, $4.38 \%$ were living with a partner, $0.59 \%$ were widowed, $2.29 \%$ were never in a union and $0.52 \%$ were divorced. Similarly a study in Egypt reported that the most common age group was the 20-29 years age group which made up $36.4 \%$ of the women studied [9]. In Nnewi, Southeast Nigeria, majority (93.6\%) of the women were also married [10]. Similarly in Tanzania majority $(92.2 \%)$ of the women were married. ${ }^{6}$ Also in India $95.7 \%$ of the women were married [11]. Majority of the women being married in the present study is expected because the average age of the women is $30.7 \pm 6.2$ years and the median age at first marriage for Nigerian women is 18.1 years [7]. Among the women in this study $23.47 \%$ were using modern family planning methods. It has been reported that the South-West geopolitical zone has the highest prevalence of use of modern family planning methods and that the national average was 9.68\% [12]. Among Northern Nigerian women, only $5.33 \%$ use modern family planning methods [13]. The great difference between the SouthWestern women and the Northern women may be because of their differences in education. While $89 \%$ of the South-Western women had formal education, only $34.1 \%$ of the Northern Nigerian women had formal education [13]. A study among Nigerian women had shown that those who had secondary education or more were 2.9 times more likely than those who had primary education or less to use modern family planning methods [12].

An interesting finding in this study is that logistic regression analysis showed that women who had a minimum of secondary education were 1.2 times more likely than those with only primary education to use modern family planning methods (CI=1.035983$1.454942, p=0.018$ ). This agrees with the findings of other authors who have reported that education increases the likelihood of using modern family planning methods. A study in the Northwest and Northeast Nigeria reported a statistically significant association between education and use of modern family planning methods [14]. In Bangladesh it was also reported that education increases the use of modern family planning methods [15]. Similarly in Nepal, the practice of modern family planning methods was higher among the educated [16]. In Namibia the educated women studied were 3 times more likely to use modern family planning methods than those who had no formal education [17]. Ainsworth $M$ et al demonstrated that schooling has a positive relationship with use of modern family planning in 14 Sub-Saharan countries even after controlling for many other variables [18]. An educated woman is more likely to be aware of the availability of contraceptives. She is also more likely to understand how contraceptives work, believe in their efficacy, hence more likely to use modern contraceptives.

Another interesting finding in our study is that the older women ( $\geq 25$ years) were 1.4 times more likely to use modern family planning than the younger women $(\mathrm{CI}=1.171135-1.872016, \mathrm{p}=0.001)$. This may be because the older women are more likely to be independent minded and financially capable hence more able to procure modern contraceptives. In Bangladesh, age was also a determinant of use of modern family planning methods [12]. Similarly, Awadalla HI demonstrated that the older women in Egypt used modern family planning more than the younger women [9]. It is also interesting to point out that the urban women were twice more likely than the rural women to use modern family planning methods (CI=1.674996-2.447385, $\mathrm{p}=<0.001)$. This is similar to the finding of a study in Egypt which reported that urban women used modern family planning methods more than the rural women [9]. Similarly, in Northeast and Northwest Nigeria it was demonstrated that the urban women used modern family planning methods more than the rural women and the difference was statistically significant [14]. This is may be because women in the urban areas are more educated than their counterparts in the rural areas. It could also be because more health facilities exist in the urban areas, hence more access to modern family planning methods.

In conclusion, the present study has demonstrated that the likelihood of using modern family planning among women in the South-Western geo-political zone of Nigeria is increased by the following variables: having at least secondary education; being 25 years old or more and urban residence. We therefore recommend the consideration of these factors in the planning of interventions to increase uptake of modern family methods in Nigeria. Measures should be taken to increase female literacy, as this will most likely lead to improved uptake of family planning among the respondents. Also resources should be channeled more to reaching the younger women and the women residing in the rural areas.

\section{Acknowledgement}

The authors wish to express gratitude to Measure DHS program for releasing the dataset at no cost to the authors.

\section{References}

1. Wikipedia (2018) Family planning.

2. Merriam-Webster (2018) Dictionary family planning. 


\section{Epidemiology international journal}

3. Brown SS, Eisenberg L (1995) The Best Intentions: Unintended Pregnancy and the Well-Being of Children and Families. National Academy Press, Washington, DC, USA.

4. World atlas (2018) The ten most populated countries in Africa.

5. World Bank (2018) Population Growth.

6. United Nations Department of Economic and Social Affairs (2018) World population projected to reach 9.7 billion by 2050 .

7. National Population Commission of Nigeria and ICF International. Nigeria Demographic and Health Survey 2013. Abuja Nigeria and Rockville Maryland, USA.

8. Measure Evaluation (2018) Demographic and Health Surveys.

9. Awadalla HI (2012) Contraception use among Egyptian women: Results from Egypt demographic and health survey in 2005. J Reprod Infertil 13(3): 167-173.

10. Igwegbe AO, Ugboaja JO, Monago EN (2009) Prevalence and determinants of unmet needs for family planning in Nnewi, Southeast, Nigeria. Int J Med Med Sci 9(8): 325-329.

11. Kidayi PL, Msuya S, Todd J, Mtuya CC, Mtuy T, et al. (2015) Determinants of modern contraceptive use among women of reproductive age in Tanzania: Evidence from Tanzania Demographic and Health Survey data. Advances in Sexual Medicine 5: 43-52.

12. Azuike EC, Ikeako LC, Azuike ED, Joe-Ikechebelu NN, Nwachukwu CC, et al. (2017) Correlates of use of modern family planning methods among women in Nigeria: A secondary analysis of NDHS 2013. Global Advanced Research Journal of Medicine and Medical Sciences 6(5): 79-85.

13. Ikeako LC, Joe Ikechebelu NN, Nwankwo BE, Onyemachi PE, Chikezie JC, et al. (2018) Determinants of use of modern family planning among northern Nigerian women: A secondary analysis of 2013 NDHS. Open Access Library Journal 5: e4521.

14. Unumeri G, Ishaku S, Ahonsi B, Oginni A (2015) Contraceptive use and its socio-economic determinants among women in Northeast and Northwest Nigeria: A comparative analysis. African Population Studies 9(2): 1851-1867.

15. Karmal SM, Islam A (2010) Contraceptive Use: Socioeconomic Correlates and Method Choices in Rural Bangladesh. Pacific J Public Health 22(4): 436-450.

16. Tuladhar H, Marahatta $R$ (2008) Awareness and practice of family planning methods in women attending Gynae OPD at Nepal Medical College Teaching Hospital. Nepal Med College J 10(3): 184 191.

17. Indongo $\mathrm{N}$ (2005) Contraceptive choice and use of methods among young women in Namibia. Afr Population Stud 22: 2.

18. Ainsworth M, Beegle K, Nyamete A (1996) The impact of women's schooling on fertility and contraceptive use: A study of fourteen Sub- Saharan African countries. The World Bank Economic Review 10(1): 85-121. 